\title{
An unusual case of cyclin-D1-positive peripheral $T$ cell lymphoma with a 11:14 translocation
}

\author{
Helen Mary Alexander • Elizabeth Young • \\ Lorna W. Harries • Miles Joyner • Paul Newman • \\ Patrick Sarsfield
}

Received: 12 February 2010 / Accepted: 8 June 2010 /Published online: 17 July 2010

(C) Springer-Verlag 2010

\begin{abstract}
Overexpression of cyclin D1 is commonly observed in human cancers. The best-known association is with mantle cell lymphoma in which there is a $\mathrm{t}(11: 14)$ translocation. We describe an unusual case of high-grade $\mathrm{T}$ cell lymphoma, presenting as rapidly enlarging, painless lymphadenopathy in an 80-year-old female. She died 13 months after presentation, having relapsed after chemotherapy. The lymph node showed diffuse effacement by blastic lymphoid cells, positive for $\mathrm{T}$ cell markers and cyclin D1. Molecular genetics investigations found $\mathrm{t}(11: 14)$ translocation. There was definite $\mathrm{T}$ cell clonality demonstrating clonal rearrangement of both $\mathrm{T}$ cell receptor gamma and beta genes but no convincing evidence of $\mathrm{B}$ cell clonality. These data represent the first documented case where deregulation of the cyclin D1 expression has been implicated in human $\mathrm{T}$ cell lymphoreticular malignancy.
\end{abstract}

Keywords Cyclin D1 - CCND1 - T cell lymphoma . $\mathrm{t}(11: 14) \cdot$ Immunohistochemical

\footnotetext{
H. M. Alexander $(\bowtie) \cdot$ P. Newman $\cdot$ P. Sarsfield

Histopathology Department,

Royal Devon and Exeter Foundation Trust,

Church Lane,

Exeter EX2 5AD, UK

e-mail: hmalex@doctors.org.uk

E. Young $\cdot$ L. W. Harries

Molecular Genetics Department,

Royal Devon and Exeter Foundation Trust,

Exeter, UK

M. Joyner

Hematology Department,

Royal Devon and Exeter Foundation Trust,

Exeter, UK
}

\section{Introduction}

Cyclin D1 is a protein encoded by the cyclin D1 (CCND1) gene and performs a vital role in normal cells, controlling the passage of cells from G1 to S phase of the cell cycle [6]. Progression through the cell cycle is tightly regulated and dependent on passage through cellular checkpoints that mark the distinction between the phases of cell division. The G1 to S checkpoint marks the switch from resting (G1) state to the DNA replication (S) phase and plays a pivotal role in the prevention of tumorigenesis. The G1/S checkpoint relies upon the action of two pathways: the p53 pathway (involved in the detection and removal of cells with damaged DNA) and the retinoblastoma ( $\mathrm{Rb}$ ) pathway (which inhibits DNA replication by negatively regulating the nuclear transcription factor E2F). Cyclin D1 is a key member of the $\mathrm{Rb}$ pathway. The interaction of cyclin $\mathrm{D} 1$ with its specific cyclin-dependent kinase ( $\mathrm{Cdk} 4)$ causes the $\mathrm{Rb}$ protein to become phosphorylated. The phosphorylation event liberates E2F from the negative regulation of $\mathrm{Rb}$ and the cell cycle proceeds $[6,13]$. The pathways are complex and many other mediators have been implicated including CCAAT/enhancer binding protein beta $(\mathrm{C} / \mathrm{EBP} \beta)$ and RASSF1A $[10,16]$.

Overexpression of cyclin D1 is commonly observed in a variety of human malignancies, for example soft tissue sarcomas [3] and lung and breast cancer [6]. The bestcharacterized example is mantle cell lymphoma where overexpression of cyclin D1 results from the translocation $\mathrm{t}(11: 14)(\mathrm{q} 13 ; \mathrm{q} 32)$. This places the cyclin D1 gene in close proximity to the immunoglobulin heavy chain gene, causing both alterations in progression through the cell cycle and also changes to apoptotic pathways. The precise mechanisms through which this deregulation promotes 
tumorigenesis are still imperfectly understood [9]. In most cases, increased levels of cyclin D1 are the result of complex oncogenic pathways, rather than a clonal mutation or rearrangement of the cyclin D1 gene [6].

We describe an unusual case of a peripheral high-grade $\mathrm{T}$ cell lymphoma (WHO classification: peripheral $\mathrm{T}$ cell lymphoma, NOS), which also showed evidence of strong positive staining with cyclin D1. Molecular genetics investigations revealed a clonal $\mathrm{T}$ cell population. Although a definite $\mathrm{B}$ cell clonal population was not detected, there was a significantly raised peak in one of the reaction profiles. We also identified a $\mathrm{t}(11: 14)$ translocation.

\section{Case report}

An 80-year-old lady presented in May 2005 with progressively enlarging, painless lymphadenopathy of the neck, axillae, and groins. Her general health was reasonable with a normal performance status but there had been modest weight loss and occasional drenching night sweats.

CT scanning confirmed bilateral, large-volume cervical lymphadenopathy extending as a confluent mass into the supraclavicular fossae, axillae, and anterior chest wall. The spleen measured $11 \mathrm{~cm}$, and there was large-volume paraaortic lymphadenopathy from the level of the renal arteries to the aortic bifurcation, extending into the iliac lymph chain and groin regions.

Blood tests at presentation revealed a high $\mathrm{LDH}$ at 948 IU/1 (240-480) but otherwise normal biochemistry. A full blood count revealed a hemoglobin of $13.6 \mathrm{~g} / \mathrm{dl}(12.0$ $16.0)$, white count of $7.2 \times 10^{9} / 1(3.6-11.0)$, eosinophils of $0.99 \times 10^{9} / 1(0.04-0.4)$, and platelets of $180 \times 10^{9} / 1(150-$ 400). The ESR was normal. Beta 2 microglobulin was elevated at $4.2 \mathrm{mg} / 1(0-2.2)$. Serum protein electrophoresis was normal. Immunoglobulin levels revealed a slightly elevated IgA at $4.69 \mathrm{~g} / \mathrm{l}(0.8-4.0)$. Direct Coombs test was negative.

Sections of the lymph node biopsy revealed diffuse effacement by sheets of large, pleomorphic, blastic lymphoid cells with vesicular nuclei, scanty cytoplasm, prominent multiple nucleoli, and frequent mitoses (Fig. 1). Populations of cells with a similar morphology were also identified in the bone marrow trephine with a paratrabecular distribution.

The patient was treated with a combination of chemotherapy using cyclophosphamide, vincristine, adriamycin, and prednisolone and responded promptly. Restaging showed minimal residual abnormalities after four courses of chemotherapy. Despite initial improvement, she died 13 months after presentation following relapse of her disease.

\section{Materials and methods}

Immunological characterization

Immunohistochemical staining was performed on formalinfixed, paraffin-embedded tissue sections using an automated immunostainer (Biogenex Optimax Plus, San Ramon, $\mathrm{CA}$ ). The following antibodies were used: CD20 (Novocastra, Newcastle Upon Tyne, UK,1:300 dilution), CD79a (DAKO, Glostrop, Denmark, 1:400 dilution), MUM1 (DAKO, 1:600 dilution), BOB1 (Novocastra, 1:50 dilution), OCT2 (Novocastra, 1:50 dilution), CD23 (Novocastra, 1:50 dilution), CD10 (Novocastra, 1:40 dilution), BCL2 (DAKO, 1:50 dilution), BCL6 (DAKO, 1:20 dilution), cyclin D1 (Novocastra, 1:40 dilution), kappa (DAKO, 1:6,000 dilution), lambda (DAKO, 1:6,000 dilution), MIB1 (DAKO, 1:200 dilution), TIA-1 (Immunotech Marsaille, France, 1:100 dilution), CD5 (DAKO, 1:20 dilution), CD3 (Novocastra, 1:100 dilution), CD4 (Novocastra, 1:20 dilution), CD8 (Novocastra, 1:40 dilution), CD56 (Monosan, Uden, Netherlands, 1:10 dilution), CD57 (Novocastra, 1:10 dilution), CD30 (Novocastra, 1:10 dilution), CD2 (Novocastra, 1:40 dilution), and CD7 (Novocastra, 1:20 dilution).

Antigen retrieval was achieved in all cases except light chains by heating to $125^{\circ} \mathrm{C}$ in a Biocare Medical Decloaking Chamber (Walnut Creek, CA) in Bull's Eye (1:20) solution and holding for $30 \mathrm{~s}$. Sections stained for kappa and lambda were heated in a Proline Microchef $950 \mathrm{~W}$ oven for $25 \mathrm{~min}$ in 1:10 Dakocytomation Target Retrieval solution. Antibody detection was by the DAKO Chem Mate detection kit in all cases except BOB1, MUM1, and OCT2 where a Biogenex-Biotin-free polymer detection kit was used. Positive controls were used with each run of immunohistochemistry.

\section{Molecular studies}

DNA was extracted from the lymph node sample to assess the presence of $\mathrm{B}$ cell and $\mathrm{T}$ cell clones and the $\mathrm{t}(11: 14$; q13q32) chromosomal translocation using the Qiagen Tissue Kit (Qiagen, Crawley, UK) according to the manufacturer's instructions. The $t[11: 14](q 13 ; q 32)$ chromosomal translocation was detected using previously published primers: MTCA, MTCB [15], LJH, and VLJH [2]. Two separate nested polymerase chain reactions (PCRs) were employed to detect the MTCA and MTCB breakpoints within the major translocation cluster region in the bcl-1 gene on chromosome 11. First- and second-round PCRs were performed in $12 \mu \mathrm{l}$ of $1 \times$ Amplitaq Gold reaction buffer II (Applied Biosystems, Warrington, UK) containing final concentrations of $2.5 \mathrm{mM} \mathrm{MgCl}_{2}$ (Applied Biosystems), $200 \mu \mathrm{M}$ dNTPs (Amersham Pharmacia Biotech, St. Albans, UK), $25 \mathrm{ng}$ each of forward and 
Fig. 1 a $\mathrm{T}$ cell lymphoma, H\&E, $\times 40$. b Positive membrane staining with CD5 $(\times 20)$. c Strong positive nuclear staining with cyclin D1 $(\times 20)$. d Negative staining with CD20. A residual follicle is seen on the left $(\times 20)$. e Positive membrane staining with $\mathrm{CD} 3(\times 20)$
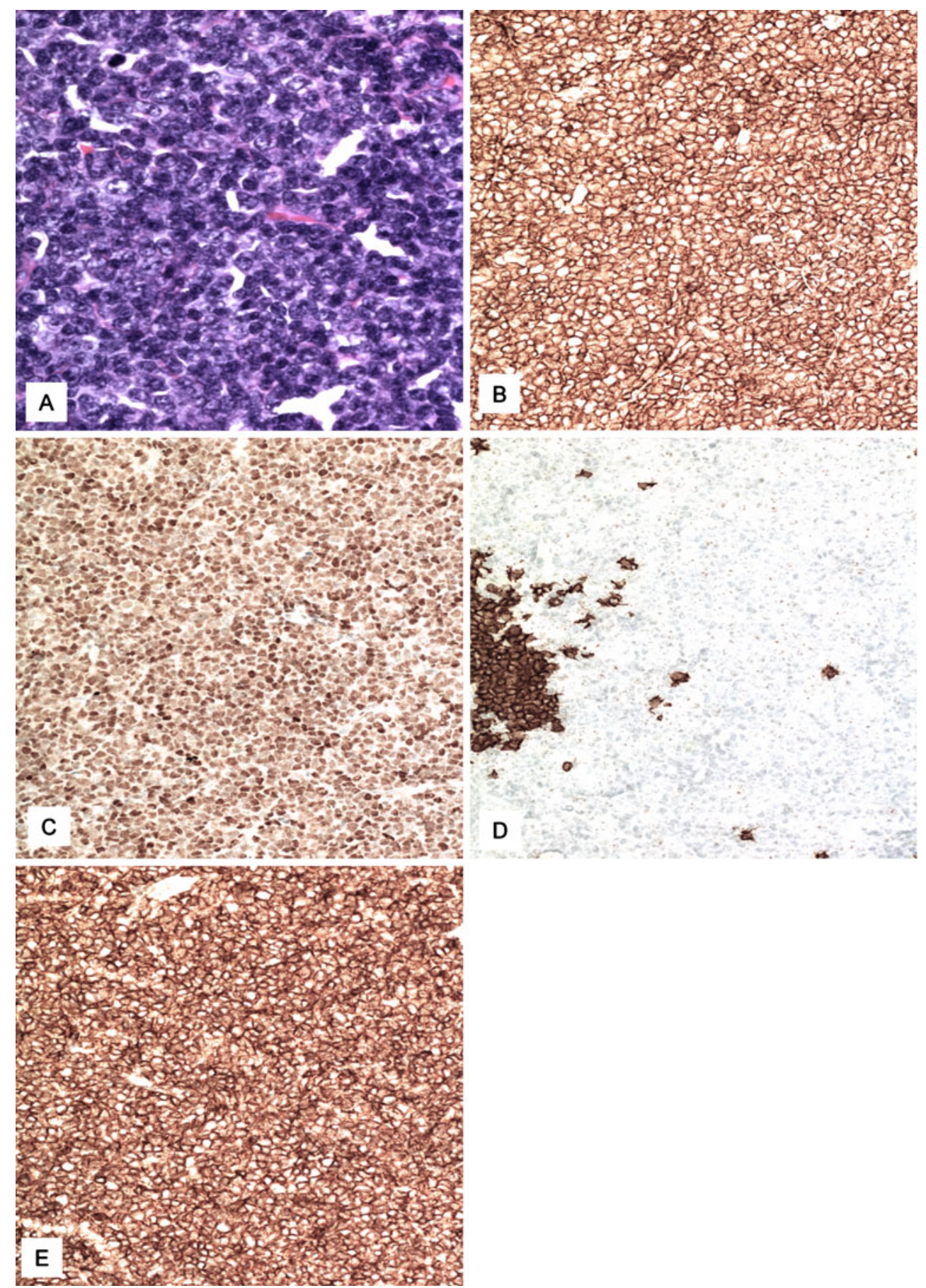

reverse primers (Severn Biotech, Kidderminster, UK), and 0.2 units of Amplitaq Gold Taq polymerase (Applied Biosystems). Forty nanograms of DNA template and $1 \mu 1$ of first-round product were added to first- and secondround reactions, respectively. All reactions were heated at $94^{\circ} \mathrm{C}$ for $10 \mathrm{~min}$ to activate the Amplitaq Gold Taq polymerase. Thermo cycling consisted of 30 cycles of $94^{\circ} \mathrm{C}$ for $1 \mathrm{~min}$ and $60^{\circ} \mathrm{C}$ for $1 \mathrm{~min}$, followed by incubation at $72^{\circ} \mathrm{C}$ for $10 \mathrm{~min}$. Thermo cycling was performed using a
Perkin Elmer 9600 thermocycler (Applied Biosystems). The MTCA and MTCB PCR products were identified using agarose gel electrophoresis.

Clonality status for Ig heavy chain and TCR $\gamma$ was determined using the methods of Ramasamay et al. [12] and Wickham et al. [14]. The presence of TCR $\beta$ rearrangements was confirmed using the Invivoscribe TCR $\beta$ kit (Invivoscribe, San Diego, USA). Reactions contained 100 ng DNA in a total volume of $25 \mu \mathrm{l}$. 


\section{Results}

Immunohistochemical stains

The majority of tumor cells showed strong membrane positivity for CD3, CD4, and CD5. The tumor cells also showed strong diffuse nuclear staining for cyclin D1 (Fig. 1). There was diffuse weak membrane positivity for CD2 and focal weak membrane positivity for CD7. BCL2 showed moderate cytoplasmic staining in approximately $60 \%$ of the tumor cells. There were admixed CD57-positive cells but the tumor cells appeared negative for this marker. CD20, CD79a, BOB1, MUM1, OCT2, CD10, CD23, CD8, BCL6, CD56, CD30, and TIA were negative. Approximately $50 \%$ of the cells stained with MIB1. There were some aggregates of small lymphocytes staining positively with CD20, BOB1, OCT2, CD10, and CD79a, which were polytypic, representing reactive $\mathrm{B}$ cell remnants, mainly towards the periphery. CD23 outlined residual follicular structures within these aggregates of B cells. The tumor cells were entirely negative for these markers. Very small numbers of isolated lymphocytes with this immunophenotype were also identified elsewhere within the tumor. There were scanty cells with granular cytoplasmic TIA positivity in particular in the extracapsular region.

\section{Molecular genetics investigations}

PCR analysis of DNA extracted from the lymph node showed the presence of the $t(11: 14 ; q 13 q 32)$ translocation. $B$ cell clonality studies of the lymph node did not detect a clonal population of cells. However, a significantly raised peak with a polyclonal background was noted in the FR2 profile. $\mathrm{T}$ cell clonality studies identified clonal populations of both the TCR beta and gamma genes (Fig. 2).

\section{Discussion}

This is an unusual case of a high-grade lymphoma confirmed by immunohistochemical and molecular investigations to be $\mathrm{T}$ cell in type but showing immunohistochemical staining for cyclin D1.

Despite its obvious involvement in B cell malignancy, CCND1 overexpression has not been associated with peripheral $\mathrm{T}$ cell lymphoma in man $[1,7,8,17]$. However, a study of $\mathrm{T}$ cell lymphomas in mice found that there was cyclin D1 overexpression in $42 \%$ (20/47) of the tumors examined [11]. Fluorescence PCR quantification of cyclin D1 expression by Elentoba-Johnson et al. in a small series of human $\mathrm{T}$ cell lymphomas found moderately high levels of cyclin D1 mRNA in one of seven (14\%) cases investigated. However, there was no evidence of increased cyclin D1 protein synthesis, and accordingly, immunohistochemical staining was negative [5]. Increased levels of cyclin D1 have also been demonstrated in association with malignant $\mathrm{T}$ cell amplified sequence $1(M C T-1)$ in human $\mathrm{T}$ cell lymphoma cell lines in vitro [7]. Elevated CCND1 transcripts have been reported in approximately $14 \%$ of PTCL [6], but no concurrent increase in cyclin D1 protein levels has been demonstrated in this or other studies $[1,4,7]$.
Fig. 2 TCR clonality studies DNA extracted from the lymph node was assessed for the presence of $\mathrm{T}$ cell beta clones using the Invivoscribe TCR $\beta$ kit (Invivoscribe, San Diego, USA) and $\mathrm{T}$ cell gamma clones using the methods as described in Wickham et al. [14]. Data were analyzed using GeneMarker software (SoftGenetics LLC). a TCR beta clonality studies. Patient DNA yielding a single product of 252 base pairs in size, representing a clonal population of cells. b TCR gamma clonality studies. Patient DNA yielding two amplified products of 166 and 176 base pairs in size, representing a clonal population of cells

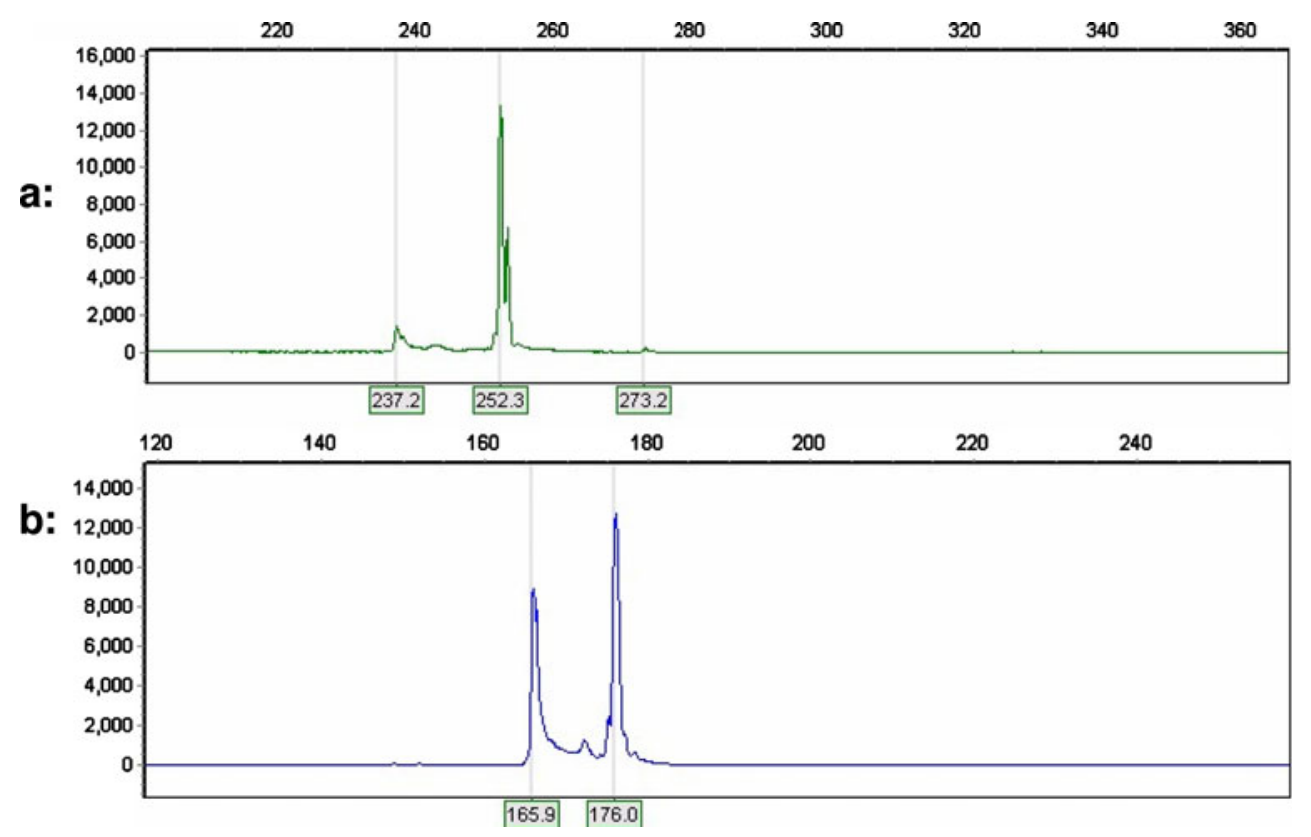


In this case, $\mathrm{T}$ cell clonality studies identified clonal populations in beta and gamma regions. B cell clonality studies demonstrated a significantly raised peak on a polyclonal background, perhaps suggestive of an abnormal $\mathrm{B}$ cell population, but no clear clonal peak. CCND1 overexpression was noted by immunohistochemistry, which may be driven by the presence of a $\mathrm{t}(11: 14 ; \mathrm{q} 13 \mathrm{q} 32)$ translocation, more typically associated with the B-cell-derived mantle cell lymphoma. Although there was no histological or immunohistochemical evidence to support the presence of a second tumor population with this pattern of differentiation, it is not possible to completely exclude a collision tumor having elements of both a peripheral $\mathrm{T}$ cell lymphoma and a mantle cell lymphoma. However, at a molecular level, no definite clonal B cell population was identified.

Although the interpretation of some aspects of the molecular findings is complex, this is unequivocally a case of a high-grade $\mathrm{T}$ cell lymphoma in which cyclin D1 is strongly expressed at the immunohistochemical level, suggesting that deregulation of cyclin D1 expression can have a role in the pathogenesis of $\mathrm{T}$ cell lymphoma.

Conflict of interest The authors declare that they have no conflict of interest.

\section{References}

1. Baba Y, Tsukuda M, Kagata H et al (2000) Nasal natural killer/T cell lymphoma: case report with molecular biological examination on Epstein-Barr virus and cell cycle regulatory p16, cyclin D1, $R b$, and $p 53$ genes. J Otolaryngol 29(2):121-125

2. Brisco MJ, Tan LW, Orsborn AM et al (1990) Development of a highly sensitive assay, based on the polymerase chain reaction, for rare B-lymphocyte clones in a polyclonal population. $\mathrm{Br} \mathrm{J}$ Haematol 75:163-167

3. Bui M, Bagui T, Boulware D et al (2007) Altered expression of cell cycle regulatory proteins in benign and malignant soft tissue neoplasms. In Vivo 21(5):729-737
4. De Vos S, Krug U, Hofmann W et al (2003) Cell cycle alterations in the blastoid variant of mantle cell lymphoma (MCL-BV) as detected by gene expression profiling of mantle cell lymphoma (MCL) and MCL-BV. Diagn Mol Pathol 12(1):35-43

5. Elenitoba-Johnson KS, Bohling SD, Jenson SD et al (2002) Fluorescence PCR quantification of cyclin D1 expression. J Mol Diagn 4(2):90-96

6. Fu M, Wang C, Li Z et al (2004) Minireview: cyclin D1: normal and abnormal functions. Endocrinology 145(12):5439-5447

7. Herbert GB, Shi B, Gertenhaus RB (2001) Expression and stabilization of the MCT-1 protein by DNA damaging agents. Oncogene 20(46):6777-6783

8. Kanavaros P, Bal M, Stefanaki K et al (2001) Immunohistochemical expression of the p53, mdm2, p21/Waf-1, Rb, p16, Ki67, cyclin D1, cyclin A and cyclin B1 proteins and apoptotic index in T-cell lymphomas. Histol Histopathol 16:377-386

9. Korz C, Pscherer A, Benner A et al (2002) Evidence for distinct pathomechanisms in B-cell chronic lymphocytic leukaemia and mantle cell lymphoma by quantitative expression analysis of cell cycle and apoptosis-associated genes. Blood 99(12):45544561

10. Lamb J, Ewen E (2003) Cyclin D1 and molecular chaperones. Implications for tumorigenesis. Cell Cycle 2(6):525-527

11. Perez de Castro IP, Malumbres M, Santos J (1999) Cooperative alterations of $\mathrm{Rb}$ pathway regulators in mouse primary $\mathrm{T}$ cell lymphomas. Carcinogenesis 20(9):1675-1682

12. Ramasamay I, Brisco M, Morley A (1992) Improved PCR method for detecting monoclonal immunoglobulin heavy chain rearrangement in B cell neoplasms. J Clin Pathol 45:770775

13. Sandal T (2002) Molecular aspects of the mammalian cell cycle and cancer. Oncologist 7(1):73-81

14. Wickham CL, Lynas C, Ellard S (2000) Detection of clonal T cell populations by high resolution PCR using fluorescently labeled nucleotides; evaluation using conventional LIS-SSCP. Mol Pathol 53(3):150-154

15. Williams ME, Swerdlow SH, Meeker TC (1993) Chromosome t $(11 ; 14)(\mathrm{q} 13 ; \mathrm{q} 32)$ breakpoints in centrocytic lymphoma are highly localised at the bcl-1 major translocation cluster. Leukemia 7 (9): $1437-1440$

16. Wong IH, Chan J, Wong $\mathrm{J}$ et al (2004) Ubiquitous aberrant RASSF1A promoter methylation in childhood neoplasia. Clin Cancer Res 10(3):994-1002

17. Zuckerberg LR, Yang WI, Arnold A et al (1995) Cyclin D1 expression in non-Hodgkin's lymphoma. Detection by immunohistochemistry. Am J Clin Pathol 103(6):756-760 